\title{
Coping with crises: Consumption and social resilience on markets
}

\section{Sebastian Koos ${ }^{1}$}

${ }^{1}$ Department of Politics and Public Administration, Universität Konstanz, Universitätstrasse 10, Konstanz, Germany

${ }^{2}$ Institute of Social Studies, University of Tartu

\section{Correspondence}

Sebastian Koos, Department of Politics and Public Administration, Universität Konstanz, Universitätstrasse 10, Konstanz, Germany. Email: sebastian.koos@uni-konstanz.de

\author{
Triin Vihalemm² $^{2}$ Margit Keller ${ }^{2}$
}

\begin{abstract}
Crises, especially economic crises are an immanent element of modern market societies. While some research has been devoted to understanding the consequences of such crises on consumption, a systematic integrative approach to this problem is still missing. In this editorial we develop an encompassing model for the study of crises and consumption, to identify and connect the different elements important for understanding and explaining the relationship. Thereafter we present the papers of this special issue and discuss their contributions, based on the proposed framework. Suggestions for future research conclude the editorial.

\section{KEYWORDS}

adaption, consumption, coping, crises, markets, model, social resilience
\end{abstract}

\section{INTRODUCTION}

Crises or 'normal accidents' (Perrow, 2011), such as economic shocks, natural disasters or terrorist attacks are a rather common feature of modern societies. In general, a crisis can be understood as some unforeseen event that creates uncertainty, threatening daily routines and putting the accomplishment of certain personal ends to a risk (Kutak, 1938). Thus, crises disrupt the taken-for granted everyday life and provoke change. The recent global financial crisis of 2008, followed by the 2010 fiscal crisis of many European states have been the largest economic shocks since the Great Depression of the 1930s. While the ensuing recession, characterized by high inflation, stagnating wages and rising unemployment raised the salience of such shocks, especially economic crises are rather frequent in capitalist economies. Since the 1970s Laeven and Valencia (2013) have counted 211 currency crises, 147 banking crises and 66 sovereign debt crises worldwide.

Consumers' everyday lives have been and are still affected by these crises on multiple levels-from job loss and decline of household income to increasing austerity in social policies. Crises also have severe impacts on the consumption patterns of people, their life chances, worldviews and well-being. Thus, crises are immanently related to changes of lifestyles, consumption patterns and routines. Understanding the responses to crisis and the 'creativity' of such action is a core problem for social scientists (Joas, 1996). People do not only passively adapt, but actively develop coping strategies and means of social resilience (Folke, 2006, Parker \& Endler, 1996). Their responses, that is, changed market demand, transformed activities and solidarities, in turn, initiate structural changes in the society.

In recent years, the concept of resilience has gained some momentum in ecology, psychology, but also in sociology and political science (Hall \& Lamont, 2013a, Maurer, 2016). Social resilience refers to 'an outcome in which the members of a group sustain their well-being in face of challenges to it' (Hall \& Lamont, 2013b, p. 13). Thus, resilience is not only as a psychological trait of people, but rather the adaptive capacity of a social system 'to absorb disturbances and re-organize while undergoing change', while at the same time opening up opportunities for 'recombination of both structures and processes, renewal of the system and emergence of new trajectories' (Folke, 2006, p. 259). Given the far-reaching economic crises since 2008 , it seems crucial to get an understanding of how people organize resilience on markets, how they cope with crises. The sociology of consumption, but also marketing research has devoted some attention to the effects of crises on consumption, yet contributions so far remain rather isolated and disciplinarily separated, using different frameworks and explanations (Ang, 2001; Kaytaz \& Gul, 2014; Lekakis, 2015; Shama, 1978). Moreover, research focuses on different aspects of the nexus between crises and consumption, studying specific purchasing patterns, householding strategies, discourses and lifestyles (Alonso, Rodríguez, \& Rojo, 2015; Hampson \& McGoldrick, 2013; Vihalemm, Keller, \& Pihu, 2016; Zurawicki \& Braidot, 2005). Existing studies have focused on different, yet mostly macro-economic, shocks in developed market economies, 
rarely comparing the influence across different countries, time or types of crises (Ang, 2001; Gerstberger \& Yaneva, 2013). ${ }^{1}$

In the present special issue, we collect research on this timely and important problem and seek to provide some answers on how consumers respond to economic shocks, how social resilience is organized and it manifests on markets as well as how long-term processes of sociocultural transformation may be initiated by changing consumer identities and values. Before discussing the contributions of the special issue, in this introduction we develop a conceptual framework for the study of crises, consumption and social resilience on markets. We start by briefly discussing existing frameworks and thereafter offer our own conceptual model. The proposed model is more encompassing and allows an analytical distinction between contextual influences, individual capabilities and different consumption strategies. We conclude by discussing how the papers of the special issue fit into our framework and help to understand coping with crises and social resilience on markets.

\section{CONCEPTUAL FRAMEWORKS FOR STUDYING THE LINK BETWEEN CRISIS AND CONSUMPTION}

Most economic shocks have important effects on the everyday of people. Yet, the way people cope with a crisis can be very different, ranging from organized reactions of consumers to individual sacrifices, saving of resources or even consuming more due to lower prices. From a sociological perspective, Lekakis (2015) distinguishes between three broader reactions to the crisis: resistance, reinforcement and resilience. Resistance refers to the usage of consumption as a means to stop objectionable market practices fuelled by the economic crisis, like boycotts targeting poor labour conditions. The notion of reinforcement describes consumption patterns focusing on the purchase of national products to support the economy, favouring a culture of ethnocentrism. Finally, resilience refers to a creative reorganization of markets, for instance by direct trade networks and cooperatives.

On a more individual or household level, people react to economic shocks most basically by either stopping to consume certain goods, reducing purchases or buying different goods, prolong certain purchases and use some goods longer. In an early attempt to model consumer reactions to economic crisis from a marketing perspective Shama (1978, 1981) distinguishes between five reactions of consumers: general adjustments, price, product, place and promotion adjustments. General adjustments refer to whether people have changed their consumption practices at all and, if so, how they changed them. For instance, whether people consume less, are more energy conscious, seek more information on shopping or discuss purchases with their partner. Price relates to all financial aspects of purchasing decisions including comparing prices shopping for bargains and using credit. Product adaptions denote all changes of the types and quality of products consumed, like temporarily avoiding the purchase of durables or substituting branded goods with private label products. Place refers to the outlet at which products are

${ }^{1}$ For an extensive overview and discussion of existing research on crisis and consumption, see Koos (2017). obtained, for instance buying at market stalls, general retailers, wholesale outlets or discount stores. Finally, promotion adjustments denote the use of and trust in promotions. While this framework makes intuitive sense, the meaning and distinctiveness of the categories remain somewhat arbitrary. To date the framework, mainly informed by a marketing perspective, has been widely used in studies on the impact of crises on consumption (Alimen \& Bayraktaroglu, 2011; Ang, 2001; Ang, Leong, \& Kotler, 2000; Hampson \& McGoldrick, 2013).

Urbonavicius and Pikturniene (2010) develop a somewhat different framework distinguishing between six behavioural patterns in response to a crisis. First, some consumers might not change their consumption at all. Second, some consumers need to drastically reduce spending in order to get by. Others might decrease consumption in order to build up savings, as a protection against potential future loss. Some consumers might even spend more money to increase the life quality on a short-term basis as long as it can be afforded. Finally, some groups that are objectively not affected by the crisis might even buy more or higher quality products, since prices are usually lower. Changes in consumer practices might also be related to the types of products and services consumed. Some authors distinguish between necessities and supplementary goods (McKenzie, 2003). Others distinguish between durables, like furniture, semi-durables, like clothes and food items (Zurawicki \& Braidot, 2005).

\section{AN ENCOMPASSING CONCEPTUAL MODEL FOR THE STUDY OF CRISIS AND CONSUMPTION}

While existing models all predict some aspect of behavioural change, they suffer from a number of shortcomings: first, the majority of frameworks focuses strongly on the purchasing aspect of consumption and neglects the usage and disposal dimension. Second, most models do neglect the broader social, cultural, economic and institutional context in which consumption is embedded. Finally, specific response strategies are rarely linked to characteristics of consumers, like social class, identity or cultural and economic resources. We seek to systematically unpack the relationship between crisis and consumer responses, by sketching the impact of different types of crises on consumer behaviour, moderated, by specific institutional arrangements and specific consumer characteristics (Figure 1).

However, it is important to emphasize that the model is based on an analytical distinction which should help to identify and sort the elements that are important in understanding and explaining consumption in crisis. Also, we have attempted to develop a conceptual model that embraces different components of the interrelationships between crises, their context and consumption. Not all of those components included in the model are equally empirically analysed in the contributions of this issue. While there is some sequencing (i.e., some initial shock as a starting point), the different elements of our model are mostly mutually related. Thus, we perceive the characteristics of consumers and the context in which they are embedded as important influencers on consumer responses, but, these responses will also have repercussions on the consumer (e.g., changing values and perceptions), and the context (e.g., changing market size, the emergence of new consumption norms or the demand for political intervention). 


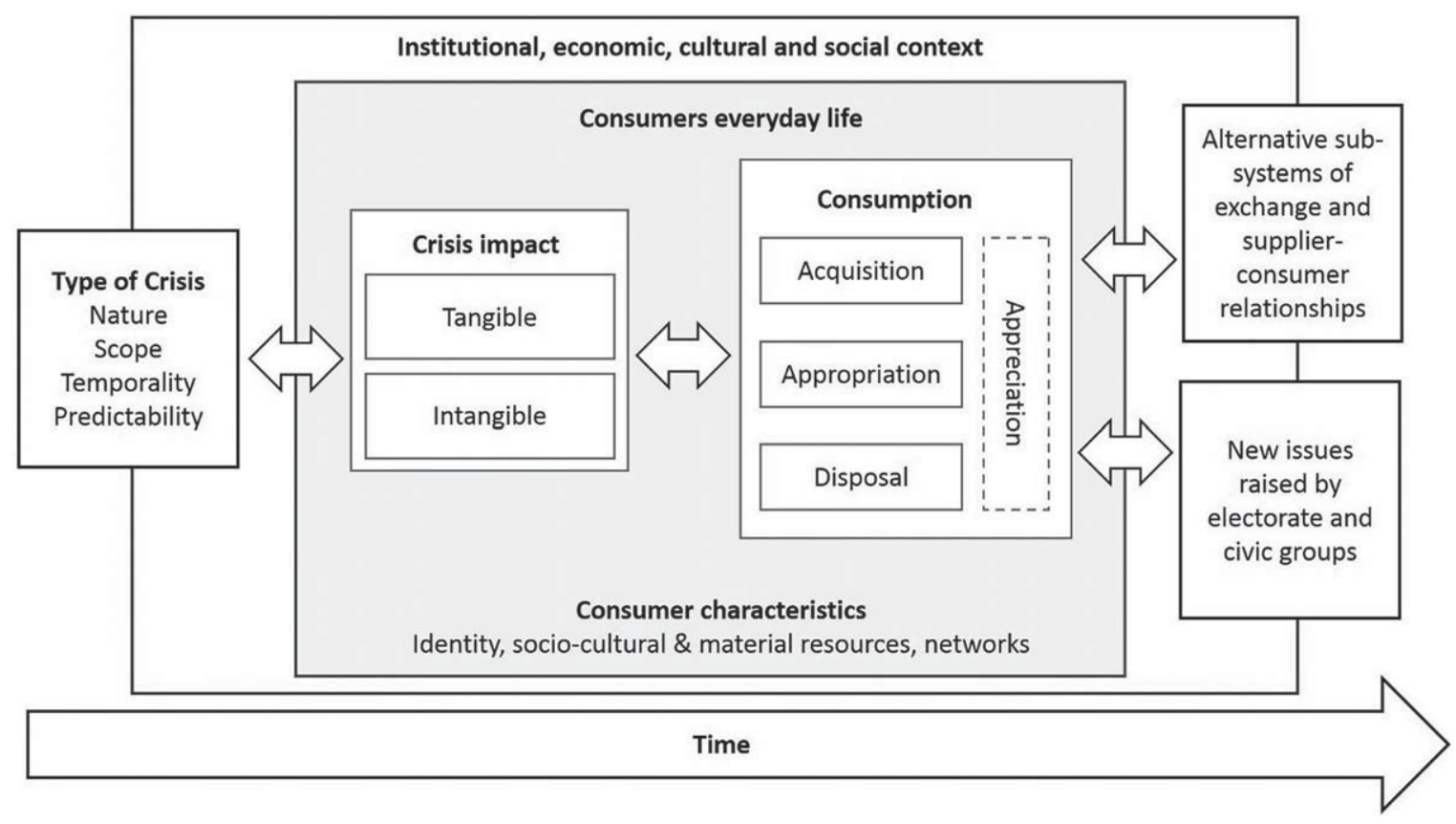

FIGURE 1 An encompassing conceptual model of crises and consumption

Source. Own depiction

\subsection{Varieties of crises}

Crises or shocks are not uniform, but vary in their very nature, number of people affected, temporal impact and predictability (Koos, 2017). Different crises might provoke different consumer reactions, thus a closer look at the characteristics of crises seems important, when studying their impact on consumers. First of all, crises can have natural causes or be man-made. Given the complex social, economic and technological systems characteristic to modern societies such man-made 'normal accidents' are inevitable (Perrow, 2011, p. 5). Second, crises differ in whether they affect an individual, a small group, a whole community, society or even world-society. Obviously, the former is not independent of the latter. Societal crises often translate into individual hardship and thus have a direct impact on people. Third, depending on the type of crisis, its temporal impact can vary strongly. Some crises have potential long-term effects, while for instance economic shocks mostly are temporary. Finally, crises differ in the extent to which they are predictable or likely (Gundel, 2005). The predictability of a crisis may have important effects on the coping strategies applied. Crises that are rather common, such as recessions, industrial accidents, or in some regions even earthquakes, can to a certain degree be expected and insured or attenuated. The very nature, level and predictability of a crisis, is very likely to shape the effects it has on social life and the coping strategies. But, how do crises impact consumers?

\subsection{Tangible and intangible effects of crises on consumers}

On the basic level there are two major ways by which aggregate crises effect individual consumers, either by a direct tangible or an indirect cognitive/emotional mechanism (Koos, 2017). First, crises can have tangible, direct ramifications on the resources available to people for their daily consumption decisions. Stagnating or declining wages, becoming unemployed, a cut in social transfers or rising prices reduce the actual monetary resources of people and thus put direct limits to their consumption options. This resource-based mechanism is rather simple, but powerful. Depriving people of monetary resources or devaluing these constrains their purchasing decisions on markets.

Second, crises do not need to have direct tangible effects on people to affect their consumption practices. Crises inflict a sense of uncertainty, thus perceptions of the crises and beliefs about potential future impacts of a crisis on one's life can lead to changing behaviour. For instance, Alonso et al. (2015, p. 69) cite a Spanish interviewee mentioning that as a consequence of the financial crisis 'uncertainty is now a part of us'. Such a predominantly cognitive mechanism is likely to be also infused with emotional strains, like fear or 'confusion'. Hence, an economic recession might lead to consuming less and differently, while not directly being affected by unemployment or even a wage cut, but by rising uncertainty or fear of some potential future impact. Crises, thus, have the potential to undermine the innate belief in the taken for granted stability and structure of our life world.

Generally, both of the described mechanisms interact in different ways and in reality are often mingled. In the first instance, where a crisis has a direct objective impact on available resources this will also inevitably be linked to cognitive and emotional reactions. Yet, in the second mechanism, a resource constraint needs not be observed to have consequences. Generally, the distinction is important to understand that crises can play out in the everyday despite real material deprivation. Empirical studies on the impact of the recent financial crises show that both tangible and intangible effects of the crises can be observed across Europe and the OECD countries, where the crisis has 
a direct effect on unemployment, financial deprivation, but also perceived job insecurity (Brian \& Patrick, 2010; Chung \& Van Oorschot, 2011; Reeskens \& van Oorschot, 2014). Such impacts differ strongly across countries and social groups. Thus, some 'groups' might face a higher risk of being subject to tangible impacts than others.

In addition, we need to bear in mind that crises to not happen in a vacuum and the transformation happening in the economic, political and cultural structures (such as the material infrastructure of markets, supply and provision systems, social policies, as well as in mental constructs of values and identities) can moderate the tangible and intangible effects of a crisis. Moreover, the impact of a crisis on consumers and on the structures in which they are embedded might themselves either reinforce or alleviate the crisis, in a kind of feedback loop.

\subsection{Changing consumption}

Crises are strongly related to change, 'so much so that the two are near synonyms' (Starke, Kaasch, \& Van Hooren, 2013, p. 6). While some consumers might choose not to react at all, others do change their behaviour in a number of ways and to different degrees. Following a definition of consumption by Warde (2005) and complemented by Halkier, Keller, Wilska, and Truninger (2017) we see consumption as a phenomenon being comprised of three components: acquisition which can involve multiple modes and ways of getting various objects (from purchasing to self-production and gift-giving), both material and immaterial (goods, services, experiences etc); appropriation which embraces all kinds of activities related to usage of goods and services. The disposal component involves everything from simple throwing away of everyday items to elaborate selling, swapping or re-using patterns that can be significantly changed during crisis. Within all components we can safely say that crises can have impacts on objects to be consumed, as well as on the ways and modes how it is done. A fourth element appreciation, which refers to sense making about consumption, is related to all other components, as a kind of meta-dimension, because all consumption activities are infused with meanings.

First, within the acquisition component of consumption we can distinguish market related changes in purchasing decisions, like buying less, buying lower quality or at a lower price, shopping at different outlets or buying different types of goods, from self-production or receiving transfers and gifts. If we wish to detail different elements of acquisition via markets even further we can draw to some extent on the framework of Shama (1978), for instance regarding the categories place and price as well as quantity and quality of products. In addition, the types of products matter, since people may distinguish between necessities and supplementary goods (McKenzie, 2003). People may also search for more information about different prices, products and outlets. We think this reflects the main purchasing related changes. Some consumers might buy smaller quantities of goods with the same quality, other might shop at discount stores for lower priced goods, but do neither change the quantity nor might try to avoid sacrifices on product quality. Outside of market-based exchange, consumers might seek alternative resource pools, for instance, intergenerational transfers or engage in subsistence production.
The usage and disposal of goods might also change. People can be expected to keep and use goods longer and postpone buying new ones. Rather than buying, consumers might start to repair and recycle. Tight budgets might also lead to a more considerate use and disposal of goods, for instance, a higher willingness of eating food that has passed its expiration date. Acquisition, appropriation and disposal components-even though analytically separated-are not fully distinguishable and are related to some degree. For instance a bundle of activities that we may label 'budgeting' intersects both the acquisition of goods and services ('for how much to buy') and the usage of goods (e.g., maintenance costs). Thus, all components need to be put in a larger context of the 'juggling' with resources within a budget, household or network.

Finally, the appreciation dimension is also very likely to be affected by crisis. While the consumer reactions described here carry a mostly economic meaning, as attempts to cope with shocks and scarcity, consumer reactions might also carry a political connotation, where specific products are boycotted or bought as a means to cope with crises more collectively. For instance, ethnocentric purchase patterns to support the own national economy for political reasons, rather than out of necessity, seem to have flourished during the recent recession (Lekakis, 2015; Smyczek \& Glowik, 2011). It is very likely that the appreciation of practices also changes collective norms, values and justifications.

\subsection{Social, cultural and material resources for resilience in consumers' everyday life}

Resilience also means activating and mobilizing latent social, cultural, or economic capital or resources (Hall \& Lamont, 2013a). The impact of crises and specific coping strategies are dependent on consumers' individual economic resources, skills, social networks, that is, different forms of capital (Bourdieu, 1984) and everyday life configurations. On the one hand, such characteristics influence belonging to social classes and specific 'risk' groups that render it more or less likely to be directly or indirectly affected by a crisis. The recent financial crises had specifically negative effects on the young, the precariously employed and the unemployed. On the other hand, such characteristics are important in determining how consumers respond to crises.

Economic and material resources are of crucial importance for any kind of consumption decision. Such resources encompass, financial assets, like saved money, stocks, household income, financial transfers, but also non-monetary resources and belongings, like a house, a car or home appliances. Resources ultimately determine the degrees of freedom in consumption decisions and confine which kind of goods and services can be consumed. Economic resources are fundamentally related to the position of people in social space (Bourdieu, 1984). They are often a result of specific occupational positions or inherited wealth and a crucial element of the stratification of society. Arising social inequalities might be at the core of coping with crises.

How people react to crises might also be related to their specific cultural capital or technical and social skills. By cultural capital we refer to the knowledge, values and beliefs that orient and guide action (Bourdieu, 1984). Those values, worldviews and identities can themselves be altered by crisis. 
Alonso et al. (2015) show how the crisis has changed class identities in Spain. By skills, we refer to (technical) knowledge that can be put to practical use. Such skills are often acquired in formal education, but also adopted from family and friends, while growing up. Technical skills can be very simple things, like the ability to prepare a meal, grow and preserve food, but also the ability to repair household appliances, clothes or even a car. Finally, social skills are the ability to address, motivate and cooperate with other actors (Fligstein, 1997). Such skills are often closely related to the social capital, the networks, ties and obligational relationships in which one is engaged. In times of crises, specific networks and the ability to ask for support might be important in developing coping strategies, both on the individual but also on a more collective level (e.g., in organizing alternative exchange networks).

Consumers (prod)use media discourses in interpreting the consequences of crisis on their individual lives, social relationships and selfidentifications. The public reflection of crisis affects the way how power relations are constructed and legitimized in the society. Public re-thinking of interrelations between ownership and consumption (i.e., sharing economy), production and consumption (i.e., communal exchanges) and citizenship and consumption (i.e., the internalisation or rejection of the hegemonic media discourses about overspending and austerity etc.) shape both consumption strategies in the traditional market and participation in the new sub-systems of exchange. Participation experience in these networks is a new emerging research area that is touched upon also in this special issue. Thus, crises can motivate citizens' mobilisation such as public protest movements, but also producers' mobilisation to seek for innovative ways of production and exchange.

Crises and consumption enter into interaction for consumers within the context of individual everyday lives. The latter can be conceptualized in different ways, but for the sake of clarity we mainly refer to socio-material arrangements (e.g., housing) the everyday routines and activities (daily schedules of domestic, professional or civic life) that consumers are embedded in. Together with individual characteristics the affordances and constraints of everyday arrangements can be understood as socio-cultural and material resources for resilience that can considerably exacerbate or alleviate the impact of crisis.

\subsection{Contextualising crises and consumption}

As we pointed out above, crises, their impact on consumers and consumer reactions do not happen in a void, but have to be understood in their institutional, economic, cultural and social context. Consumers are embedded in specific regional or national structures and belief systems, which might not only directly affect how crises unfold, impact consumers and how consumers react to such shocks, but also whether a crisis emerges in the first place. First, man-made crises might be avoided or at least less likely to arise, if specific regulations are in place. The housing bubble and the rise of securitization leading to the global financial crisis of 2008 was enabled by changes in the regulation of the US banking industry (Fligstein \& McAdam, 2012). Thus, regulations of specific industries and technologies might help to prevent certain crises or render their impact less harmful.
Second, the institutional context in which a crisis emerges might have important implications for who is affected and to what extent as well as how consumers cope. For instance, labour market policies can protect workers form being laid off during economic recessions. In countries where people have far reaching social rights in a developed welfare state, they might be differently affected and also react very differently than in countries lacking such arrangements. According to a classical typology by Polanyi (1992 [1957]) there are three types of instituted exchange, which are central in bolstering the effects of a crisis, namely, redistribution, market exchange and reciprocity. Redistribution by a (welfare) state helps people to cope with crises, for instance by providing unemployment benefits or social assistance. Market exchange helps by providing private insurance schemes, that can be purchased on markets and insure against all kind of risks, from sickness to death. Reciprocity, allows sharing resources as for instance, found in family exchange. Thus, the effect of crisis on consumption also depends on the institutional infrastructure available in different nation states.

Moreover, the make-up of the economy, for instance the primacy of the industrial sector versus the service or agricultural sector, as well as a countries' dependence on world markets renders its population more or less vulnerable to economic crises. Likewise, consumers' reactions to crises might be contingent on specific economic and market structures and cultural repertoires. The availability of discount or online stores, food banks and debt counselling services might be important to deal with shocks. Finally, a culture of coping, past experience with crises, strong civic ties and solidarity networks, might attenuate the effect of a crisis. We deem it important to consider such contextual differences, also to understand how specific policies, market structures or cultures can help to overcome crises.

Importantly, these structures and cultures might also be affected themselves by crisis. Thus, rather than assuming a stable pattern of influence there is a dynamic relationship between crisis, consumers and the contexts in which they are embedded. Economic crisis are likely to affect the supply of goods, the employment perspectives, political structures and even culture, for instance through changing media discourses.

\subsection{The temporality of crises}

An important, but rarely acknowledged, aspect is the timing and temporality of crisis and their impact on consumer reactions. Once a crisis emerges, consumers might either quickly change their consumption patterns, or wait until they cannot suspend such a decision anymore. The timing might leave them more or less leeway for creative and organized responses. Moreover, the durability and persistence of changes in consumption patterns need to be better understood. Consumers might either return to their old routines once a crisis is over or they stick with the newly developed strategies and routines. Given much of consumption is rather habitual, once routines have changed it seems rather unlikely for them to directly be reversed. Some new practices might even be considered superior to old ones, yet, over time, some patterns are likely to change again. Thus, crises effects on 
consumption might be sticky, and the end of a crisis might not lead to a direct return to pre-crisis levels of spending. Another important issue with regard to the temporality of crisis is the public reflection of its long-term impact to the social mobility prospects, responsibility and social justice that may, in turn, also affect consumption strategies and demand for political intervention.

\subsection{Alternative systems of exchange and political mobilization}

Finally, social resilience denotes a collective process of coping with crisis. In this respect organisations and networks play a crucial role, on the one hand, by creating new means of exchange and altered producer consumer relationships, on the other hand, in the form of collective political action. The former manifests for instance in direct trade networks or in the so-called sharing economy, where alternative ways of exchange are created (Wahlen \& Laamanen, 2017). Those new subsystems are at least rhetorically aiming to alter the profit-maximising market rationale and establish other logics of exchanges, based on economic egalitarianism de-commodification and de-ownership (Schor, Fitzmaurice, Carfagna, Attwood-Charles, \& Poteat, 2016). Such alternative subsystems create opportunities for consumers to engage in production and consumption, outside of traditional market arrangements. The latter encompasses political action, like voting or participation in demonstrations, to push for political solutions of the crisis-induced problems. Collective political movements, like the anti-austerity movement, provide collective vehicles to voice consumer interests and address both politics and the market.

\section{CONTRIBUTIONS OF THE PAPERS OF THE SPECIAL ISSUE}

The contributions in this issue analyse several of the above-mentioned aspects of crisis and consumption across a variety of countries: Brazil, Finland, Germany, Russia, Spain, the United Kingdom and the United States The responses and expressions of resilience during the crisis are highlighted from consumers' engagement in the appropriation of goods and new ways of consumer-producer relationships (Blättel-Mink et al.; Garner), paradigmatic changes in the interconnections between consumption and ownership (Lindblom \& Lindblom) as well as changing perceptions of consumption practices and class belonging (Alonso et al.; Castilhos). Moreover, studies analyse people's responses to rising prices (Hampson and McGoldrick; Berdysheva and Romanova), their (differentiating) access to the alternative ways of self-supply during the crisis (Boost and Meier) and the reconfiguration and levelling effects of consumer expenditures across four different crises in Russia (Radaev and Kotelnikova).

Boost and Meier (2017) for Germany and Castilhos, Fonseca and Bavaresco (2017) for Brazil examine the changes of consumption patterns, especially the acquisition dimension of it: smart shopping, delaying and prioritising of purchasing and self-production (see Figure 1) and their relations with social self-esteem among lower middle class, whose ability to maintain their social status depends heavily on their resilience during the crisis. Boost and Meier stress that the de-commodified practices of resilience require considerable material resources (i.e., land for cultivation) and social network resources as well as crafting and other skills that may not easily be available. Therefore, in their view partially de-commodified and weak prosumption practices constitute little innovation. Castilhos et al. stresses a fruitful combination of primary and secondary socialisation among new middle classes as a source of resilience during crisis: lower class socialisation equips individuals with specific socio-cultural resources (ethics of struggle and trusting family relations) that intertwine with the market-mediated forms of secondary socialization and building of a new middle class identity. He argues that this hybrid is an important source of resilience and helps to maintain the social aspirations of and strive for material improvement and belief in self-achievement of the new middle class. Alonso, Fernandez, \& Rojo in their analysis of public perceptions of the crisis in Spain, are counter-arguing any positive impact of crisis on the individual mobility prospects of people. The authors are visioning the high potential of collective political mobilisation that is based on the doubt and resistance to the increasingly hegemonic selfresponsibilisation discourse (living beyond one's means). Thus, they refer to the changing identities and class perceptions of consumers and the prospects for collective mobilisation as an outcome of crisis to the institutional, economic, cultural and social context. This resistance may take different forms across the countries. In this issue, Berdysheva and Romanova (2017), explain Russians' reactions to increase of consumer prices (such as price boycotts) as mundane and micro-scale forms of protest and emancipation as consumers, despite the fact that the readiness for any collective mobilization is very low. Their paper shows nicely how crises induce changes in the appreciation of prices and how this in turn aggregates to a new norm of consumer behaviour. Hampson and McGoldrick (2017) explore the impact of financial well-being and frugality norms on consumer price consciousness, showing that economic resources are a prime explanation of price consciousness (forming an important component of the appreciation dimension of consumption). The contributions to this issue refer to the long-term impact of crisis: in parallel with the immediate and tangible responses that affect the supply and require adaptations from producers and marketers (see Hampson \& McGoldrick in this issue) the more intangible co-effects of the consumers' resilience can also lead to the gradual transformation of values, identities and initiate new forms of exchange (see Figure 1).

In this issue, several articles tackle the possible innovative impact of crisis in the form of alternative sub-systems of exchange, building of supplier-consumer relationships and via changing perceptions of ownership (see Figure 1).

Two articles in this issue, one by Garner (2017) and the other by Blättel-Mink, Boddenberg, Gunkel, Schmitz, and Vaessen (2017) explain the innovative aspect of crisis by presenting two cases of agricultural exchange that alter consumer-producer relationships. Blättel-Mink et al. in their analysis of Community-Supported Agriculture highlight crisis as a motivator of social innovation that aims to establish more egalitarian social relations and less exploitation of natural resources. Garner in his contribution explains supportive buying of farmers' products as a form of de-commodification by categorizing them relational or communal exchanges that involve trust, dependence, a shared history, loyalty and 
other social factors. Some authors have elsewhere raised suspicion about the role of new sub-systems of exchange to alter the existing power relations and class (Schor et al., 2016). In this issue, Lindblom \& Lindblom (2017) point towards similar indications. They question whether the ideas of a sharing economy, that is, the new conceptualization of links between the ownership of goods, could find more followers during the crisis. Their findings reveal that lower social classes with limited economic resources support traditional ways of possession of goods and the new practices are more likely to emerge with the generation replacement rather than be facilitated by economic crises. They emphasize the probability of deepening social differentiation based on consumption patterns between the educated and higher social status groups who are eager to participate in the new forms of exchange and lower education and status groups. Thus, the submissions in this special issue offer important addition to the emerging discussion about new forms of exchanges.

Finally, the paper by Radaev and Kotelnikova takes the demanded comparative perspective seriously and compares the reconfigurations of consumer expenditures across four different economic crises in Russia since 1990. They find some support of a levelling effect between different socio-economic groups, where the more affluent cut their spending the most. Interestingly the changes in expenditure are similar across the different crises.

\section{CONCLUSION AND FUTURE RESEARCH}

Economic crises seem to be an inherent characteristic of capitalist market economies. While we have gained some understanding of how crises affect consumption there remains much to be done. Few studies compare different types of crises or the effects of one crisis across different contexts (but see Radaev and Kotelnikova in this issue). Such perspectives would be important to gain a better understanding of the differential impact of different crises and of the moderating capacity of institutional arrangements as well as various dimensions of everyday life and socio-cultural and material resilience. Moreover, the timing and temporality of crises are rarely considered. Since consumer reactions can potentially have worsening effects on economic crises, due to a decline in demand, it is important to understand how sticky changes in consumer behaviour are and if and when consumers return to old consumption patterns. Future studies need to analyse how individual coping practices are related to consumer characteristics and institutional arrangements in which they are embedded as well as on how exactly crises affect (or do not) everyday consumption activities on the appropriation, appreciation and disposal dimensions, not only acquisition, on which there exists more research already (this is reflected in the studies by Boost and Meier; Castelhos; Alonso et al.). Such a perspective would allow a better understanding of different repertoires of resilience and the conditions that facilitate and constrain their development. However, the present collection of research papers is an important step in the right direction, providing important insights, which inform future research in the field.

\section{ACKNOWLEDGMENT}

We would like to thank all authors, the numerous reviewers and the editor, Katherine Hughes, for their continuous support of this special issue.

\section{REFERENCES}

Alimen, N., \& Bayraktaroglu, G. (2011). Consumption adjustments of turkish consumers during the global financial crisis. Ege Akademik Bakis (Ege Academic Review), 11(2), 193-203.

Alonso, L. E., Fernández Rodríguez, C. J., \& Rojo, R. I. (2017). "I think the middle class is disappearing": Crisis perceptions and consumption patterns in Spain. International Journal of Consumer Studies, 41(4), 389-396.

Alonso, L. E., Rodríguez, C. J. F., \& Rojo, R. I. (2015). From consumerism to guilt: Economic crisis and discourses about consumption in Spain. Journal of Consumer Culture, 15(1), 66-85.

Ang, S. H. (2001). Crisis marketing: A comparison across economic scenarios. International Business Review, 10(3), 263-284.

Ang, S. H., Leong, S. M., \& Kotler, P. (2000). The Asian apocalypse: Crisis marketing for consumers and businesses. Long Range Planning, 33(1), 97-119.

Berdysheva, E., \& Romanova, R. (2017). Rethinking prices during an economic crisis: Calculation as a new mode of consumer behaviour in Russia. International Journal of Consumer Studies, 41(4), 397-403.

Blättel-Mink, B., Boddenberg, M., Gunkel, L., Schmitz, S., \& Vaessen, F. (2017). Beyond the market - New practices of supply in times of crisis: The example community-supported agriculture. International Journal of Consumer Studies, 41(4), 415-421.

Boost, M., \& Meier, L. (2017). Resilient practices of consumption in times of crisis - Biographical interviews with members of vulnerable households in Germany. International Journal of Consumer Studies, 41(4), 371-378.

Bourdieu, P. (1984). La distinction: Critique sociale du jugement. Paris: Les Ed. de Minuit.

Brian, K., \& Patrick, L. (2010). From crisis to recovery: The causes, course and consequences of the great recession. Paris: OECD Publishing.

Castilhos, R. B., Fonseca, M. J., \& Bavaresco, V. (2017). Consumption, crisis, and coping strategies of lower class families in Brazil: A sociological account. International Journal of Consumer Studies, 41(4), 379-388.

Chung, H., \& Van Oorschot, W. (2011). Institutions versus market forces: Explaining the employment insecurity of European individuals during (the beginning of) the financial crisis. Journal of European Social Policy, 21(4), 287-301.

Fligstein, N. (1997). Social skill and institutional theory. American Behavioral Scientist, 40(4), 397-405.

Fligstein, N., \& McAdam, D. (2012). A theory of fields. Oxford: Oxford University Press.

Folke, C. (2006). Resilience: The emergence of a perspective for socialecological systems analyses. Global Environmental Change, 16(3), 253-267.

Garner, B. (2017). Communicating social support during crises at the farmers' market: A social exchange approach to understanding customer-farmer communal relationships. International Journal of Consumer Studies, 41(4), 422-430.

Gerstberger, C., \& Yaneva, D. (2013). Analysis of Eu-27 household final consumption expenditure-Baltic countries and Greece still suffering most from the economic and financial crisis. Luxembourg: Eurostat Statistics in Focus 2/2013, 1-7.

Gundel, S. (2005). Towards a new typology of crises. Journal of Contingencies and Crisis Management, 13(3), 106-115. 
Halkier, B., Keller, M., Wilska, T.-A., \& Truninger, M. (2017). Consumption research revisited: Charting of the territory and introducing the handbook. In M. Keller, B. Halkier, T.-A. Wilska, \& M. Truninger (Eds.), Routledge handbook on consumption. London: Routledge.

Hall, P. A., \& Lamont, M. (2013a). Social resilience in the neoliberal era. Cambridge: Cambridge University Press.

Hall, P. A., \& Lamont, M. (2013b). Introduction. In P. A. Hall \& M. Lamont (Eds.), Social resilience in the neoliberal era (pp. 1-31). Cambridge: Cambridge University Press.

Hampson, D. P., \& McGoldrick, P. J. (2013). A typology of adaptive shopping patterns in recession. Journal of Business Research, 66(7), 831-838.

Hampson, D. P., \& McGoldrick, P. J. (2017). Antecedents of consumer price consciousness in a turbulent economy. International Journal of Consumer Studies, 41(4), 404-414.

Joas, H. (1996). The creativity of action. Chicago: University of Chicago Press.

Kaytaz, M., \& Gul, M. C. (2014). Consumer response to economic crisis and lessons for marketers: The Turkish experience. Journal of Business Research, 67(1), 2701-2706.

Koos, S. (2017). Crises and consumption. In M. Keller, B. Halkier, T. Wilska, \& M. Truninger (Eds.), Routledge Handbook on Consumption (pp. 131-142). Oxford: Routledge.

Kotelnikova, Z., \& Radaev, V. (2017). Recomposition and levelling of consumption expenditures across four economic shocks in Russia, 19942014. International Journal of Consumer Studies, 41(4), 439-448.

Lekakis, E. J. (2015). Economic nationalism and the cultural politics of consumption under austerity: The rise of ethnocentric consumption in Greece. Journal of Consumer Culture, doi: 10.1177/1469540515586872, 1-17.

Lindblom, A., \& Lindblom, T. (2017). De-ownership orientation and collaborative consumption during turbulent economic times. International Journal of Consumer Studies, 41(4), 431-438.

Maurer, A. (2016). New perspectives on resilience in socio-economic spheres. Wiesbaden: Springer.

McKenzie, D. J. (2003). How do households cope with aggregate shocks? Evidence from the Mexican Peso Crisis. World Development, 31(7), 1179-1199.

Parker, J. D. A., \& Endler, N. S. (1996). Coping and defense: A historical overview. In M. Zeidner \& N. S. Endler (Eds.), Handbook of coping: Theory, research, application (pp. 3-23). New York: Wiley.

Perrow, C. (2011). Normal accidents: Living with high risk technologies. Princeton: Princeton University Press.
Polanyi, K. (1992). [1957]. The economy as instituted process. In M. Granovetter \& R. Swedberg (Eds.), The sociology of economic life (pp. 29-51). Boulder: Westview Press.

Reeskens, T., \& van Oorschot, W. (2014). European feelings of deprivation amidst the financial crisis. Effects of welfare state effort and informal social relations. Acta Sociologica, 57(3), 191-206.

Schor, J. B., Fitzmaurice, C., Carfagna, L. B., Attwood-Charles, W., \& Poteat, E. D. (2016). Paradoxes of openness and distinction in the sharing economy. Poetics, 54, 66-81.

Shama, A. (1978). Management $\&$ consumers in an era of stagflation. The Journal of Marketing, 42(3), 43-52.

Shama, A. (1981). Coping with stagflation: Voluntary simplicity. The Journal of Marketing, 45(3), 120-134.

Smyczek, S., \& Glowik, M. (2011). Ethnocentrism of polish consumers as a result of the global economic crisis. Journal of Customer Behaviour, 10(2), 99-118.

Starke, P., Kaasch, A., \& Van Hooren, F. (2013). The Welfare state as crisis manager. Explaining the diversity of policy responses to economic crisis. Houndmills: Palgrave Macmillan.

Urbonavicius, S., \& Pikturniene, I. (2010). Consumers in the face of economic crisis: Evidence from two generations in Lithuania. Economics \& Management, 15, 827-834.

Vihalemm, T., Keller, M., \& Pihu, K. (2016). Consumers during the 20082011 economic crisis in Estonia: Mainstream and grass roots media discourses. Italian Sociological Review, 6(1), 57.

Wahlen, S., \& Laamanen, M. (2017). Sharing economies. In M. Keller, B. Halkier, T.-A. Wilska, \& M. Truninger (Eds.), Routledge handbook on consumption. London: Routledge.

Warde, A. (2005). Consumption and theories of practice. Journal of Consumer Culture, 5(2), 131-153.

Zurawicki, L., \& Braidot, N. (2005). Consumers during crisis: Responses from the middle class in Argentina. Journal of Business Research, 58 (8), 1100-1109. 